\title{
Pkm Scale Up Dan Pengembangan Produk Industri Hadycraft Desa Beringin Kecamatan Lubuk Pakam Kabupaten Deli Serdang Sumatera Utara
}

\author{
Andi Supriadi Chan ${ }^{1}$, Nofriadi ${ }^{2}$, Annalisa Sonaria hasibuan ${ }^{3}$ \\ 1,2,3 Politeknik Negeri Medan, Medan, Indonesia \\ e-mail ; andisupriadi@polmed.ac.id , nofriadi@polmed.ac.id , annalisahasibuan@polmed.ac.id
}

\begin{abstract}
Abstrak:
Desa beringin merupakan Mayoritas penduduknya adalah dominan ditempati oleh masyarakat transmigran dan pendatang. Rata-rata mereka yang berasal dari suku jawa dan melayu. dilihat dari letak geografisnya maka mata pencarian utama masyarakat desa beringn adalah pertanian ,peternakan Nelayan dan UMKM. Dilihat dari letak desa beringin yang berada pada dataran rendah maka jenis tanah disini adalah tanah kering sehingga tanaman yang ada didominasi oleh pertanian seperti padi , perikanan dan usaha mikro lainnya yang memiliki Potensi untuk di kembangkan.salah satunya adalah usaha handycraft Suka Maju berupa kerajinan berbahan dasar kayu seperti pembuatan kandang, sangkar burung dan tusuk sate. Usaha ini dikelola oleh beberapa orang dan memanfaatkan masyarakat sekitar sebagai karyawan. Beberapa permasalahan yang dihadapi oleh kelompok produktif ini seperti kekurangan teknologi alat mesin dalam setiap proses poduksi yang dilakukan , baik dari kegiatan pengolahan bahan baku, pengemasan hingga pemasaran dan manajemen SDM. Tujuan pengabdian kepada masyarakat yang dilakukan oleh Tim Pengabdi ini untuk menyelesaiakan permasalahan yang dihadapi oleh mitra UMKM Handycraft Suka Maju dengan penerapan Iptek yang dibuat untuk menyelesaikan permasalahan dengan cara penggunaan mesin kerja, Pelatihan dalam penggunaan alat kerja , Pelatihan Keahlian kerja, Desain Kemasan dan Pelatihan Kreatifitas, serta pemanfaatan teknologi dan social media dalam promosi dan penjualan. desain kemasan penjualan diberikan kepada mitra untuk mendukung Nilai jual produk yang telah dihasilkan.setelah itu akan diberikan pelatihan dan pemberdayaan kepada kelompok produktif tersebut terhadap penggunaan dan perawatan alat yang diberikan serta pelatihan manajemen SDM yang dimiliki agar dapat berkembang menjadi lebih baik dan mandiri serta pengenalan pentingnya merek dagang pada produk.
\end{abstract}

Kata Kunci: PKM , Produksi ,Desa Beringin , Handycraft , UMKM.

\begin{abstract}
:
Banyan village is the majority of the population is dominantly occupied by transmigrants and migrants. On average they are from the Javanese and Malay tribes. Judging from its geographical location, the main livelihoods of the Beringn village community are agriculture, livestock, fishermen and MSMEs. Judging from the location of the banyan village which is in the lowlands, the type of soil here is dry land so that the existing plants are dominated by agriculture such as rice, fisheries and other micro-enterprises that have the potential to be developed. such as making cages, bird cages and skewers. This business is managed by several people and utilizes the surrounding community as employees. Some of the problems faced by this productive group, such as the lack of machine tool technology in every production process carried out, from raw material processing, packaging to marketing and HR management activities. The purpose of community service carried out by the Service Team is to solve problems faced by MSME Handycraft Suka Maju partners with the application of science and technology made to solve problems by using work machines, training in the use of work tools, work skills training, packaging design and creativity training, as well as the use of technology and social media in promotion and sales. Sales packaging designs are given to partners to support the selling value of the products that have been produced. After that, the productive groups will be given training and empowerment on the use and maintenance of the tools provided
\end{abstract}


as well as training on HR management so that they can develop to be better and more independent as well as an introduction to the importance of trademark on the product.

Keywords: Beringin Village, Handycraft, Management, Product, Packaging

\section{Pendahuluan}

Lubuk pakam adalah sebuah kecamatan Kabupaten di deli serdang provinsi Sumatra Utara, Indonesia.kecamatan ini ini memiliki luas wilayah $31,25 \mathrm{~km}^{2}$ dan berpenduduk sebanyak 96.038 jiwa. Salah satu desa yang berada di lubuk pakam ini adalah desa beringin. Desa yang berada di dataran rendah 10 DPL di atas permukaan laut. Karena berada di ketinggian tersebut mempunyai iklim yang panas dan kering dengan suhu berkisar antara 32 sampai $37^{\circ} \mathrm{C}($ BPS 2019).

Desa beringin adalah penduduk yang dominan ditempati oleh masyarakat transmigran dan pendatang. Rata-rata didominasi oleh suku jawa dan melayu. dilihat dari letak geografisnya maka mata pencarian utama masyarakat desa beringn adalah pertanian ,peternakan Nelayan dan UMKM. Dilihat dari letak desa beringin yang berada pada dataran rendah maka jenis tanah disini adalah tanah kering sehingga tanaman yang ada didominasi oleh pertanian seperti padi, perikanan dan usaha mikro lainnya yang memiliki Potensi untuk di kembangkan.

Posisi desa beringin pada dasarnya juga terletak dikawasan pesisir pantai, sehingga memungkinkan utuk dikembangkan sektor parawista, kuliner dan kerajinan tangan. Khusus pada sektor kerajinan tangan dimana perkembangannya cukup pesat, seperti kebutuhan akan hobi masyarakat seperti kandang burung, Tempat Penetasan Telur Unggas, tusuk sate untuk kebutuhan makanan dan masih banyak lainnya.

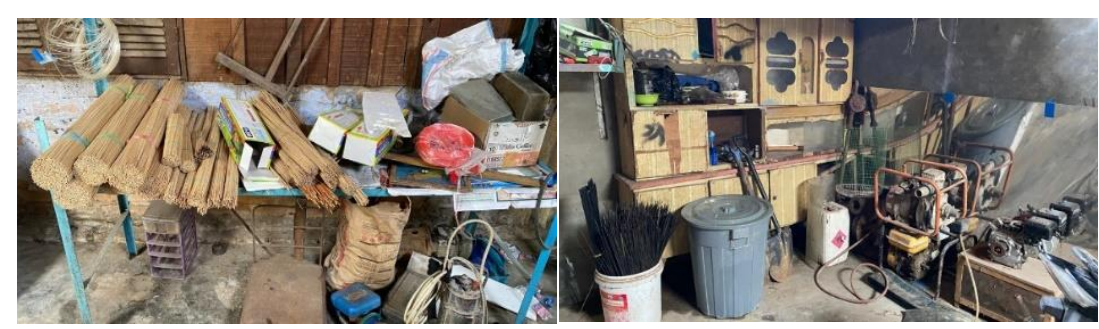

Gambar 1.1. Jenis Usaha UMKM Suka Maju

Pandemi Covid-19 yang terjadi secara global tentu saja berdampak terhadap berbagai sektor terutama di sektor ekonomi.Dampak perekonomian ini tidak hanya di rasakan secara domestik, namun juga terjadi secara global. International Monetary Fund (IMF) yang memproyeksikan ekonomi global akan tumbuh minus di angka 3\%(Hardilawati 2020). Di Indonesia, Hal ini tentunya juga memiliki dampak yang cukup signifikan terhadap pariwisata, sektor perdagangan, industri termasuk Pelaku Usaha Mikro, Kecil dan Menengah (UMKM)(Covid19.go.id 2020). 
Berdasarkan riset lapangan dan diskusi dengan kelompok handycraft milik pak toto di desa beringin, permintaan akan kebutuhan kerajinan di desa tersebut sangat tinggi, dalam sehari ada lebih dari 5 permintaan pembuatan perlengkapan berbahan dasar kayu. Seperti kandang burung, kandang penetasan telur unggas. Rak lemari, sangkar burung bahkan tusuk sate dalam jumlah besar. Padahal pada kelompok tersebut masih sedikit karyawan yang dimiliki dikarenakan tidak banyak karyawan yang memiliki kompetensi dan keahlian di bidang tersebut(Radius Setiyawan and Sri Lestari 2020). Dan juga peralatan yang digunakan masih seadanya. Sehingga menghambat dalam proses pengerjaan terhadap permintaan masyarakat yang tinggi.

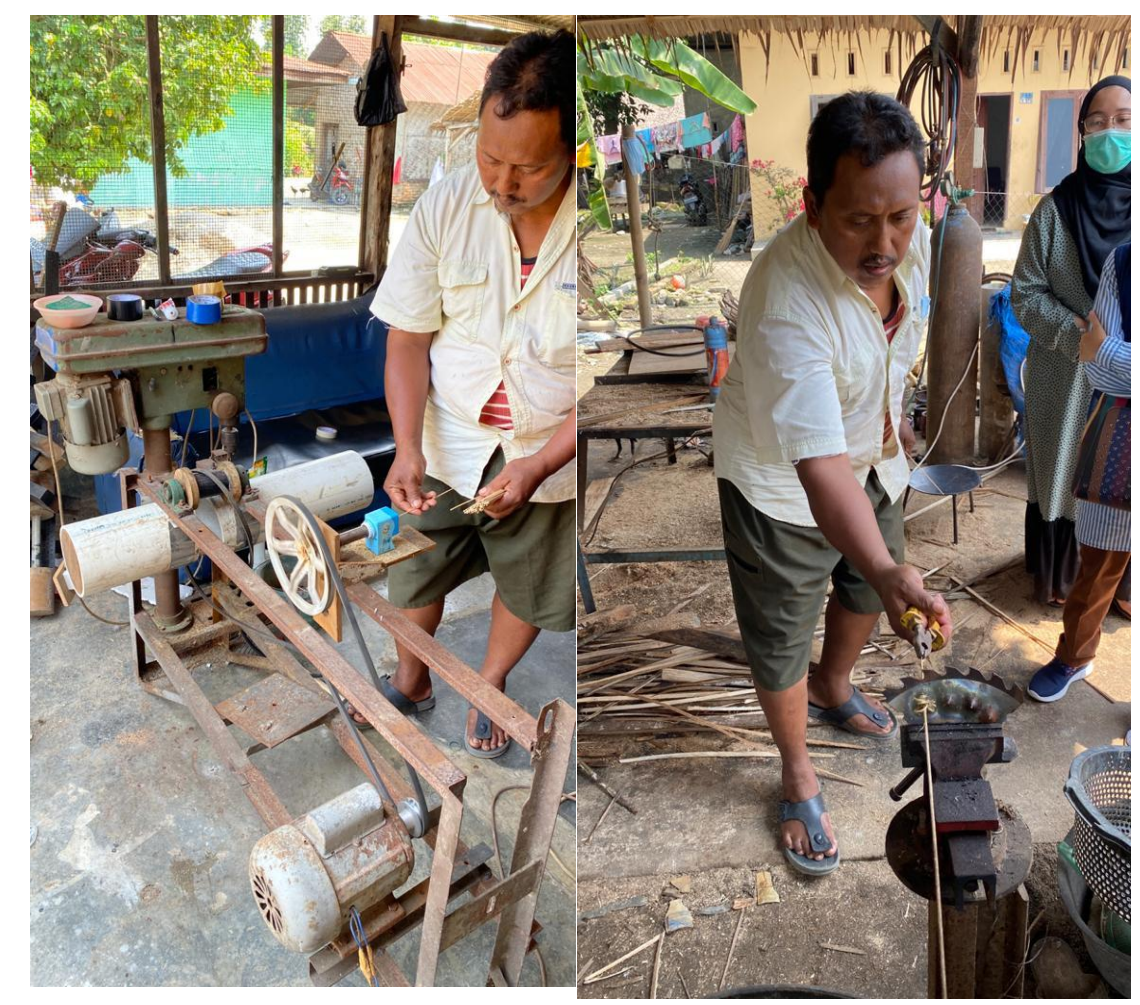

Gambar 1.2 Kegiatan masih menggunakan alat seadanya dan manual

Usaha handycraft di desa beringin ini sudah mengerjakan 5 karyawan tetap dan karyawan lepas yang berasal dari masyarakat sekitar. Hal ini dikarenakan pengelola usaha ini berencana untuk memberdayakan masyarakat sekitar untuk menambah skill dan kemampuan agar dapat secara mandiri membuat usaha yang serupa(SAPUTRO 2019). Dikarenakan masih keterbatasan perlengkapan terutama mesin pemotong kayu dan mesin bubut kayu serta pelatihan dalam penggunaan mesin untuk mendukung kemampuan karyawan agar dapat memproduksi dengan kualitas yang lebih baik dan kapasitas yang lebih besar.

Kemudian dari sisi desain hasil dari hadycraft tersebut masih bias dikembangkan lebih lanjut dari sisi desain dan pengemasan(Herliyani 2021). Hal ini perlu dilakukan karena tidak adanya kemampuan dan keahlian dari kelompok usaha handycraft pada desa beringin. Dengan adanya pengemasan dan desain produk yang lebih baik dan variatif dapat meningkatkan keinginan pembeli untuk melakukan transaksi kembali. Dan juga menambah nilai jual dari karya yang dihasilkan oleh kelompok handycraft pada desa beringin. 
Dan dari sisi penjualan yang masih konvensional hanya menerima pesanan dari warga sekitar dan yang kenal saja. Usaha handycraft ini sebenarnya punya peluang bisnis yang besar. Misalnya saja untuk kebutuhan tusuk sate permintaan sangatlah tinggi dan dibutuhkan sampai ke kota medan. Dengan pemanfaatan teknologi seperti social media ataupun e-commerce(Rizal, Safrizal, and Fuad 2020), usaha handycraft di desa beringin ini dapat memperluas pasar penjualan sehingga dapat menjadi salah satu pelopor UMKM yang berkembang dan memajukan desa serta dapat memberdayakan masyarakat desa dengan jumlah yang lebih besar.

\section{Metode}

Adapun pihak-pihak yang terlibat dalam kegiatan ini sebagai berikut:

a. Tim Pelaksana kegiatan program pengabdian kepada masyarakat pada desa beringin tim memiliki keahlian yang berbeda-beda.

b. Mahasiswa jurusan Teknik Komputer informatika yang akan membantu merancang, membangun desain kemasan dan pemasaran sesuai kebutuhan usaha handycraft di desa beringin..

c. Pemerintah desa beringin baik aparat desa maupun kelompok usaha handycraft yang sudah memberikan izin untuk pengabdian.

Metode dan Tahapan Pengabdian,Tahapan-tahapan pelaksanaan(Chan and Azwanti 2018) kegiatan sebagai berikut:

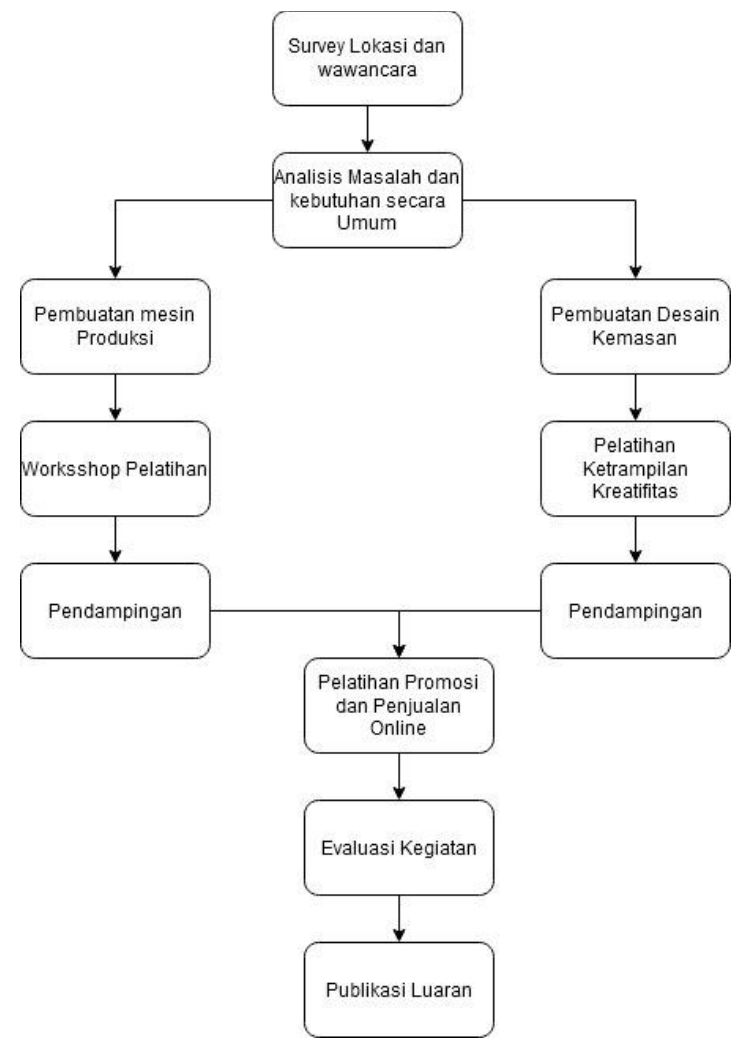

Gambar 3.1 Tahapan Pelaksanan Kegiatan 
Tabel 3.1 Penjelasan Tahapan Pelaksanaan Kegiatan

\begin{tabular}{|c|c|c|}
\hline & Tahapan Kegiatan & Penjelasan \\
\hline 1. & $\begin{array}{l}\text { Survei Lokasi } \\
\text { danWawancara }\end{array}$ & $\begin{array}{l}\text { Tahapan melakukan survey ke lokasi desa beringin dan } \\
\text { melakukan wawancara dengan pengelola usaha handycraft } \\
\text { tentang permasalahan yang dihadapi. }\end{array}$ \\
\hline 2. & $\begin{array}{l}\text { Analisis masalah dan } \\
\text { kebutuhan Secara } \\
\text { Umum }\end{array}$ & $\begin{array}{l}\text { Tahapan ini tim menganalisis permasalahan dan solusi } \\
\text { permasalahan mitra }\end{array}$ \\
\hline 3. & $\begin{array}{l}\text { Penyediaan Mesin } \\
\text { Potong dan mesin } \\
\text { Bubut Kayu }\end{array}$ & $\begin{array}{l}\text { Tahapan ini mengatasi permasalahan dengan } \\
\text { menyediakan mesin bubut dan mesin potong kayu. } \\
\text { Mesin produksi untuk memberikan manfaat sebagai } \\
\text { berikut: } \\
\text { a. Mempercepat kerja dalam produksi } \\
\text { b. Mempermudah dalam melakukan beberapa } \\
\text { kegiatan kerja } \\
\text { c. Mempersingkat antrian kerja dalam proses } \\
\text { d. Memberikan hasil dan kualitas lebih baik daripada } \\
\text { sebelumnya }\end{array}$ \\
\hline & Workshop & $\begin{array}{l}\text { Tahapan ini tim memberi pelatihan dengan praktik } \\
\text { langsung. Peserta workshop ini (karyawan dan masyarakat } \\
\text { sekitar yang berminat) akan dilatih untuk mengoperasikan } \\
\text { mesin produksi dan keahlian dalam bekerja membuat } \\
\text { handycraft. }\end{array}$ \\
\hline & Pendampingan & $\begin{array}{l}\text { Kegiatan pendampingan ini dilakukan setelah kegiatan } \\
\text { workshop selesai dilakukan. Pendampingan merupakan } \\
\text { penguatan materi workshop, dimana karyawan akan } \\
\text { diberikan kemampuan untuk meningkatkan kreatifitas } \\
\text { desain produk akan disupervisi agar mampu menciptakan } \\
\text { produk handycraft yang lebih bervariasi. Kegiatan } \\
\text { pendampingan akan dilakukan secara kontinyu, yaitu } \\
\text { komunikasi online dan mengunjungi langsung di Desa } \\
\text { beringin pada waktu yang telah ditentukan, atau } \\
\text { disesuaikan dengan permintaan Mitra. }\end{array}$ \\
\hline & \multicolumn{2}{|c|}{$\begin{array}{l}\text { Metode yang digunakan untuk mengatasi permasalahan kreatifitas dan keahlian } \\
\text { kerja yaitu ceramah, diskusi, tanya jawab, demo, praktik dan Workshop. }\end{array}$} \\
\hline 4. & $\begin{array}{l}\text { Pendaftaran merek } \\
\text { dagang produk serta } \\
\text { pemasaran social } \\
\text { media dan e- } \\
\text { commerce }\end{array}$ & $\begin{array}{l}\text { Tahapan ini untuk mengatasi permasalah mengenai tidak } \\
\text { adanya kemasan produk dan masih tradisional dalam } \\
\text { pemasaran pada kelompok usaha di desa beringi. Adapun } \\
\text { tahapan sebagai berikut } \\
\text { 1. Pendaftaran Merek Dagang } \\
\text { 2. Pemberian desain kemasan produk } \\
\text { 3. Pelatihan penggunaan social media dan e- } \\
\text { commerce untuk penjualan. }\end{array}$ \\
\hline
\end{tabular}




\begin{tabular}{|l|l|l|}
\hline & & $\begin{array}{l}\text { Metode yang digunakan untuk mengatasi permasalahan } \\
\text { Diskusi, tanya jawab, Praktik dan demo. }\end{array}$ \\
\hline 6. & Laporan & $\begin{array}{l}\text { Tahapan ini tim melakukan penyusunan laporan kegiatan } \\
\text { sebagai pertanggung jawaban kegiatan. }\end{array}$ \\
\hline 7. & Publikasi & $\begin{array}{l}\text { Tahapan ini melakukan publikas di jurnal ilmiah, media } \\
\text { massa, Video kegiatan secara Online dan merek dagang. }\end{array}$ \\
\hline
\end{tabular}

\section{Hasil dan Pembahasan}

\subsection{Persiapan Kegiatan}

Pada tahap awal pelaksanaan program dilaksanakan kegiatan berupa pemberian alat dan kegiatan pelatihan, persiapan peralatan, peserta kegiatan pelatihan dilaksanakan bersama tim pengusul didasari oleh analisis situasi yang dibuat berdasarkan permasalahan yang dihadapi oleh mitra. kegiatan ini dilaksanakan pada Bulan November 2021 yang juga melibatkan peran serta aktif peserta program pengabdian kepada masyarakat untuk membuat skala prioritas program yang dilaksanakan. Perencanaan ini berjalan dengan sangat baik berkat peranan aktif tim pelaksana dan peserta yang menjadi mitra program.

Kegiatan pemberian alat berupa mesin gergaji mesin ukir, mesin bor duduk dan spray gun untuk meningkatkan kapasitas produksi pembuatan handycraft pada desa beringin.

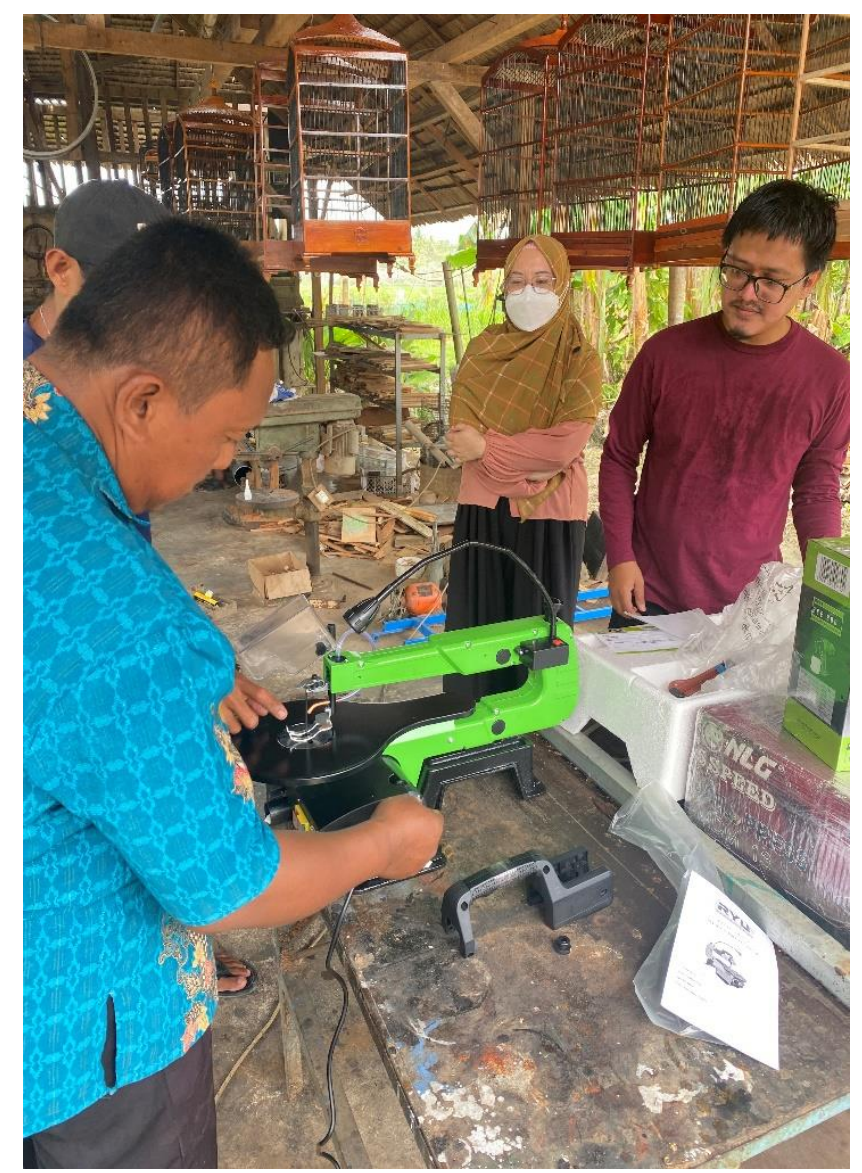




\subsection{Pelaksanaan Kegiatan}

Setelah penyerahan semua peralatan dan bahan dilakukan. Maka tahapan selanjutnya pelaksanaan kegiatan. Kegiatan dilaksanakan kedalam 2 tahap :

1. Pelatihan penggunaan Alat

Sebelum peserta melaksanakan kegiatan peserta dipandu cara penggunaan untuk masing-masing alat yang telah diberikan.Uraian kegiatan berupa pemahaman pentingnya keamanan dan teknis dalam penggunaan alat untuk produksi, hal ini dikarenakan untuk keamanan saat bekerja agar tidak menimbulkan resiko cedera saat penggunaan alat yang telah diberikan.

Setelah peserta memahami mengenai penggunaan alat tersebut kemudian Peserta mulai melakukan ujicoba terhadap masing-masing alat.

2. Pemanfaatan e-commerce sebagai media promosi

Peserta diajarkan mengenai teknik penggunaan aplikasi, Mulai dari cara peserta mendaftarkan produk, mendaftarkan user, proses posting dan lain sebagainya.

\subsection{Evaluasi Kegiatan}

Evaluasi kegiatan diberikan melalui uji penggunaan alat terhadap seluruh peserta. Berikut kesimpulan yang didapat dari hasil evaluasi peserta

a. Peserta memahami dengan baik bagaimana cara penggunaan alat produksi yang sudah diberikan.

b. Peserta juga sudah bisa menginputkan beberapa gambar dalam aplikasi seperti (Input data barang, data deskripsi produk, , dan penulisan artikel e-commerce)

c. Peserta sangat antusias untuk menerapkannya di e-commerce masing-masing..

d. Setelah diadakan pelatihan pemahaman peserta semakin meningkat akan pentingnya penggunaan aplikasi e-commerce untuk pemasaran dan penggunaan alat produksi yang telah diberikan.

\subsection{Luaran yang dicapai}

Luaran yang dicapai di tuliskan pada tabel berikut ini.

\begin{tabular}{|c|c|c|}
\hline Mitra Kegiatan & $:$ & Gapoktan Suka Maju Desa Beringin \\
\hline Jumlah Mitra & : & 10 orang \\
\hline Pendidikan Mitra & : & $\begin{array}{l}\cdot \text { S3 - orang } \\
\cdot \text { S2 -. orang } \\
\cdot \text { S1 -orang } \\
\cdot \text { Diploma -orang } \\
\cdot \text { SMA - } 2 \text { orang } \\
\cdot \text { SMP -2 orang } \\
\cdot \text { SD - } 6 \text { orang } \\
\cdot \text { Tidak Berpendidikan - orang }\end{array}$ \\
\hline
\end{tabular}




\begin{tabular}{|c|c|c|}
\hline $\begin{array}{l}\text { Permasalahan Mitra: Teknologi, } \\
\text { Manajemen, Sosial-Ekonomi, Hukum, } \\
\text { Keamanan, Lainnya }\end{array}$ & : & $\begin{array}{l}\text { Pemasaran produk yang masih } \\
\text { bersifat konvensional dan } \\
\text { tradisional.Keterbatasan alat kerja } \\
\text { dalam pembuatan Handycraft pada } \\
\text { usaha di desa beringin. Masih } \\
\text { minimnya pengetahuan dan keahlian } \\
\text { yang dimiliki oleh karyawan dalam } \\
\text { kegiatan pembuatan handycraft dan } \\
\text { tidak adanya keahlian dalam } \\
\text { penggunaan alat kerja. Belum } \\
\text { adanya merek dagang produk yang } \\
\text { dimiliki oleh usaha handycraft untuk } \\
\text { penjualan sehingga kemasan dan } \\
\text { nilai jual yang kurang menarik. }\end{array}$ \\
\hline $\begin{array}{l}\text { Status Sosial Mitra: Pengusaha Mikro, } \\
\text { Anggota Koperasi, Kelompok } \\
\text { Tani/Nelayan, PKK/Karang Taruna, } \\
\text { Lainnya (Tuliskan yang sesuai) }\end{array}$ & : & $\begin{array}{l}\text { Status sosial Mitra adalah } \\
\text { pengusaha mikro untuk usaha } \\
\text { rumah tangga yang belum } \\
\text { memperoleh izin usaha. }\end{array}$ \\
\hline LOKASI & & $\begin{array}{l}\text { Desa Beringin, Kecamatan Lubuk } \\
\text { Pakam Tuan Kabupaten Deli } \\
\text { Serdang }\end{array}$ \\
\hline Jarak PT ke Lokasi Mitra & & $45 \mathrm{KM}$ \\
\hline $\begin{array}{l}\text { Sarana Transportasi: Angkutan Umum, } \\
\text { Motor, Jalan Kaki (Tuliskan yang } \\
\text { sesuai) }\end{array}$ & & $\begin{array}{l}\text { Sarana transfortasi menuju ke mitra } \\
\text { menggunakan mobil dan taksi } \\
\text { online }\end{array}$ \\
\hline $\begin{array}{l}\text { Sarana Komunikasi: telepon, internet, } \\
\text { surat, fax, tidak ada sarana } \\
\text { komunikasi (tuliskan yang sesuai) }\end{array}$ & & $\begin{array}{l}\text { Sarana Komunikasi kepada mitra } \\
\text { menggunakan telepon. }\end{array}$ \\
\hline \multicolumn{3}{|l|}{ IDENTITAS } \\
\hline Tim PKM & & $\begin{array}{l}\text { Andi Supriadi Chan,S.Kom.,M.Kom, } \\
\text { Nofriadi S.Pd.,M.T , Annalisa } \\
\text { Sonaria Hasibuan,S.Pd.,M.Pd }\end{array}$ \\
\hline Jumlah Dosen & & 3 orang \\
\hline Jumlah Mahasiswa & & 2 orang \\
\hline Gelar Akademik Tim & & $\begin{array}{l}\text { S-3 - } 0 \text { orang } \\
\text { S2 sebanyak } 3 \text { orang } \\
\text { S1 - orang }\end{array}$ \\
\hline Jenis Kelamin & & $\begin{array}{l}\text { Laki-laki } 2 \text { - orang } \\
\text { Perempuan } 1 \text { orang }\end{array}$ \\
\hline \multicolumn{3}{|l|}{ AKTIVITAS PKM } \\
\hline $\begin{array}{l}\text { Metode Pelaksanaan Kegiatan: } \\
\text { Penyuluhan/Penyadaran, } \\
\text { Pendampingan, Pendidikan, Demplot, } \\
\text { Rancang Bangun, Pelatihan, } \\
\text { Manajemen Usaha, Pelatihan Produksi, } \\
\text { Pelatihan Administrasi, Pengobatan, } \\
\text { Lainnya (tuliskan yang sesuai) }\end{array}$ & & $\begin{array}{l}\text { Pelaksanaan kegiatan dilakukan } \\
\text { melalui kegiatan pelatihan } \\
\text { penggunaan alat produksi, } \\
\text { Pendampingan dan pelatihan } \\
\text { kepada Gapoktan di Desa Beringin, } \\
\text { dan Pemberian peralatan produksi } \\
\text { berupa mesin bor duduk, spray gun }\end{array}$ \\
\hline
\end{tabular}




\begin{tabular}{|c|c|c|}
\hline & & $\begin{array}{l}\text { dan mesin ukir untuk menambah } \\
\text { peralatan Produksi Gapoktan untuk } \\
\text { membantu peningkatan produksi } \\
\text { usaha rajutannya }\end{array}$ \\
\hline Waktu Efektif Pelaksanaan Kegiatan & & 45 Hari \\
\hline \multicolumn{3}{|l|}{ EVALUASI KEGIATAN } \\
\hline Keberhasilan & & Berhasil \\
\hline \multicolumn{3}{|l|}{ INDIKATOR KEBERHASILAN } \\
\hline Keberlanjutan Kegiatan di Mitra & & Berlanjut/ \\
\hline Kapasitas Produksi & & $\begin{array}{l}\text { Sebelum PKM jumlah karyawan } \\
\text { yang dapat diberdayakan untuk } \\
\text { membantu usaha Gapoktan hanya } 2 \\
\text { orang, kini setelah PPM jumlah } \\
\text { perempuan yang dapat } \\
\text { diberdayakan untuk membantu } \\
\text { produksi usaha rajutan menjadi } 8 \\
\text { orang. }\end{array}$ \\
\hline Omzet per bulan & & Kurang lebih 1 Juta Rupiah \\
\hline Persoalan Permasalahan Mitra & & Terselesaikan \\
\hline \multicolumn{3}{|l|}{ KONTRIBUSI MITRA } \\
\hline Peran Serta Mitra Dalam Kegiatan & : & Aktif \\
\hline Kontribusi Pendanaan & & $\begin{array}{l}\text { Menyediakan (Menyediakan } \\
\text { Tempat) }\end{array}$ \\
\hline Peranan Mitra & : & $\begin{array}{l}\text { - Objek Kegiatan } \\
\text {-Subjek Kegiatan }\end{array}$ \\
\hline \multicolumn{3}{|l|}{ KEBERLANJUTAN } \\
\hline Alasan Keberlanjutan Kegiatan Mitra & : & Keputusan bersama \\
\hline USUL PENYEMPURNAAN PKM & : & \\
\hline Model Usulan Kegiatan & : & $\begin{array}{l}\text { Pelaksanaan PKM sebaiknya } \\
\text { dilaksanakan dengan melibatkan } \\
\text { pihak Desa }\end{array}$ \\
\hline $\begin{array}{l}\text { Potret Permasalahan lain yang } \\
\text { terekam }\end{array}$ & & $\begin{array}{l}\text { Mitra masih membutuhkan } \\
\text { pendampingan untuk membuat } \\
\text { Kataloq Produksi hasil Handycraft } \\
\text { dan pendampingan untuk kegiatan } \\
\text { pemasaran produk }\end{array}$ \\
\hline \multicolumn{3}{|l|}{\begin{tabular}{|l} 
LUARAN PROGRAM PKM \\
\end{tabular}} \\
\hline Jasa & & Ada, berupa Pelatihan \\
\hline Metode atau Sistem & & Tidak ada \\
\hline Produk/Barang & & Tidak ada \\
\hline Paten & & Tidak ada \\
\hline Publikasi (Artikel/Proceeding) & & Draft \\
\hline Publikasi Media Masa & : & $\begin{array}{l}\text { - Terpublikasi di } \\
\text { OkeMedan.com } \\
\text { - Video yang dapat diakses } \\
\text { online } \\
\text { (Youtube) }\end{array}$ \\
\hline
\end{tabular}


pada mitra PKM, Gapoktan Desa beringin dengan usaha handycraft masih membutuhkan kelanjutan bantuan yaitu berupa pendampingan untuk pemasaran produk usaha handycrat agar bisa menembus pasar luar lubuk pakam, seperti kota medan dan sekitarnya. Ia berharap kegiatan PKM ini masih bisa dilanjutkan dengan bentuk bantuan dikhususkan pada pendampingan usaha untuk pemasaran produk, melalui pembuatan katalog serta media pemasaran.

Tim PKM berupaya untuk dapat memaksimalkan pelaksanaan kegiatan PKM ini, maka walaupaun kegiatan PKM telah selesai dilakukan Tim tetap melakukan komunikasi dengan mitra dengan menanyakan kegiatan yang telah dilakukan setelah dilaksanakan PKM. Harapan Tim PKM, pada masa mendatang kegiatan ini dapat dilanjutkan dengan mitra yang binaan Gapoktan desa yang memperoleh pelatihan usaha hadnycraft lebih banyak mungkin dengan asal desa yang berbeda serta dilengkapi strategi pemasaran produk usaha handycraft yang diajarkan dan didampingi pelaksanaannya sehingga mitra benar-benar mahir termasuk membantu menyediakan katalok produksi hadnycraft .

\section{Kesimpulan}

Berdasarkan hasil pelaksanaan kegiatan pengabdian kepada masyarakat, diperoleh kesimpulan dan saran sebagai berikut:

a. Kendala keterbatasan alat dapat diatasi dengan penerimaan alat produksi berupa mesin ukir duduk, mesin bor duduk dan spray gun yang diberikan Tim PKM.

b. Usaha handycraft di Desa beringin Kecamatan Deli Serdang mulai memahami memiliki strategi untuk mengembangkan usaha, walaupun masih membutuhkan pendampingan promosi melalui E-commerce.

c. Handycraft desa beringin sudah memahami cara penggunaan alat produksi dengan baik dan benar sehingga keamanan dalam proses produksi dapat dicapai.

d. Usaha handycraft pada desa beringin kini memperoleh tambahan 4 pegawai yang dapat diberdayakan sebagai karyawan freelance ikut memproduksi handycraft karena telah memperoleh bantuan alat dan pelatihan sehingga dapat menambah kapasitas produksi.

\section{Ucapan Terima Kasih}

Pengabdian pada masyarakat ini dapat terlaksana dengan bantuan berbagai pihak. Untuk itu, pada kesempatan ini diucapkan terima kasih yang sebesar-besarnya kepada Bapak/Ibu Tim P3M Politeknik Negeri Medan, terima kasih telah membantu dan menjadi tim kerjasama yang baik untuk mendukung kegiatan penelitian dan pengabdian masyarakat di lingkungan Politeknik Negeri Medan. 


\section{Daftar Pustaka}

BPS. 2019. "Kecamatan Lubuk Pakam Dalam Angka." 3-51.

Chan, Andi Supriadi, and Nurul Azwanti. 2018. "PEMBINAAN KEWARGANEGARAAN DIGITAL SERTA KOMUNIKASI DIGITAL BAGI MASYARAKAT PERUMAHAN GRIYA PRATAMA." 2(1):91-95.

Covid19.go.id. 2020. "No Title." Www.Covid19.Go.Id.

Hardilawati, Wan laura. 2020. "Strategi Bertahan UMKM Di Tengah Pandemi Covid-19." Jurnal Akuntansi Dan Ekonomika 10(1):89-98.

Herliyani, Elly. 2021. "OPTIMALISASI PERAN UMKM PENGERAJIN HANDYCRAFT DALAM MENUNJANG OPERASIONALISASI USAHA DI MASA PANDEMI." 1997-2002.

Radius Setiyawan, and Sri Lestari. 2020. "PEMBERDAYAAN EKONOMI UKM DENGAN ECOPRODUK HANDICRAFT DI JEDONG SEKARPUTIH BALONGPANGGANG GRESIK." 1(1):111.

Rizal, Yani, Safrizal, and Muhammad Fuad. 2020. "Pendampingan Pengembangan Desa Dan Manajemen Usaha Produk Kerajinan Anyaman Pandan Di Desa Alue Dua Muka'O Kecamatan IDI Rayeuk Kabupaten Aceh Timur." Jurnal Ilmiah Pengabdian Kepada Masyarakat 2(2):434-46.

SAPUTRO, TRI AGUNG TEGAR AJI. 2019. STRATEGI PENGEMBANGAN DAN PEMASARAN PADA HANDYCRAFT PIJAR EMAS UNTUK MEMPERTAHANKAN BISNIS DI MASA COVID-19. Vol. 1. 